Revue

Revue de l'histoire des religions

de l'histoire des religions

$2 \mid 2010$

Varia

\title{
Ernest RENAN, Averroès
}

présenté par Ali Benmakhlouf, Paris, Éditions Koutoubia, 2008, 186 p., $19 \mathrm{~cm}, 14,50 €$.

Xavier Kieft

URL : http://journals.openedition.org/rhr/7592

DOI : $10.4000 /$ rhr.7592

ISSN : 2105-2573

Éditeur

Armand Colin

Édition imprimée

Date de publication : 1 juin 2010

Pagination : 259-260

ISBN : 978-2200-92656-4

ISSN : 0035-1423

Référence électronique

Xavier Kieft, "Ernest RenAn, Averroès », Revue de l'histoire des religions [En ligne], 2 | 2010, mis en ligne le 26 janvier 2011, consulté le 22 septembre 2020. URL : http://journals.openedition.org/rhr/7592 ; DOI : https://doi.org/10.4000/rhr.7592

Ce document a été généré automatiquement le 22 septembre 2020.

Tous droits réservés 


\title{
Ernest RENAN, Averroès
}

\author{
présenté par Ali Benmakhlouf, Paris, Éditions Koutoubia, 2008, 186 p.,
} $19 \mathrm{~cm}, 14,50 €$.

\section{Xavier Kieft}

\section{RÉFÉRENCE}

Ernest RENAN, Averroès, présenté par Ali Benmakhlouf, Paris, Éditions Koutoubia, 2008, 186 p., $19 \mathrm{~cm}, 14,50 €$.

1 Fondée sur l'idée simple mais louable de faire connaître au grand public l'un des ouvrages responsables de la « construction légendaire » (p. 8 et 11) d'Averroès, ce livre est présenté par Ali Benmakhlouf comme le moyen d'une «déconstruction » (p. 13) de cette figure. Plusieurs pistes suggestives sont ainsi proposées dans sa préface, de la critique des erreurs de jugement de l'auteur à la remise en question de l'opposition entre la libre pensée et la religion, jusqu'à l'application de la méthode de lecture de l'historien à son œuvre même. Mais encore faut-il offrir au lecteur les moyens convenables pour procéder à une telle déconstruction. Et, de ce point de vue, la présente édition est très insuffisante.

2 D'abord, on se demande pourquoi, du livre de Renan, Averroès et l'averroïsme, il ne reste ici que la première partie consacrée au Commentateur. La déconstruction de la légende ne pourrait-elle s'appuyer sur la présentation du devenir de l'averroïsme ? En outre, si l'on peut comprendre que les textes ajoutés en appendice à l'occasion de la seconde édition ne soient pas reproduits (l'édition présentée par Alain de Libera et parue en 1997 chez Maisonneuve \& Larose constituant de ce point de vue un notable précédent), pourquoi avoir maintenu l'avertissement de Renan (légitimement supprimé en 1997), dans lequel ceux-ci sont annoncés, page 23 ? Tout montre que le travail éditorial est ici bâclé, comme le souligne, par exemple, le fait que l'édition utilisée par A. Benmakhlouf (qui n'est évidemment pas la présente, mais celle, indisponible aujourd'hui, de Calmann-Lévy, 1949) n'est indiquée qu'à la page 16, alors qu'elle est déjà citée, sans références, dès la première page de la préface. Dans la même veine, on ne s'étonne 
même plus, arrivé à la page 20, de constater l'absence pure et simple de la note 16, dont seul demeure l'appel orphelin. On l'a compris, ce volume est, au mieux, inutile et, au pire, agaçant. On ne saurait trop recommander, à celui que la lecture d'Averroès et l'averroïsme ou les analyses pertinentes d'A. Benmakhlouf intéressent, de lire l'Averroès de ce dernier paru aux Belles Lettres en 2003, et de l'accompagner de la réédition du livre de Renan parue en 2004 chez Ennoia, ou d'un exemplaire des autres éditions citées ici, voire plus simplement encore de le télécharger sur Internet. Voilà un bien mauvais départ pour une jeune maison d'édition.

\section{AUTEURS}

\section{XAVIER KIEFT}

Université Paris IV - Sorbonne. 